\title{
T cell dominated inflammatory reactions in the bronchioles of asymptomatic asthmatics are also present in the nasal mucosa
}

\author{
L.W. Poulter ${ }^{1}$, A. Norris ${ }^{2}$, C. Power ${ }^{2}$, A. Condez 1 , H. Burnes ${ }^{3}$, B. Schmekel ${ }^{4}$ \\ and C. Burke ${ }^{2}$
}

${ }^{1}$ Department of Immunology, Royal Free Hospital School of Medicine, London NW3 2QG, England;

${ }^{2}$ Department of Respiratory Medicine, James Connolly Memorial Hospital, Dublin, Ireland; ${ }^{3}$ Royal

Victoria Eye and Ear Hospital, Dublin, Ireland and ${ }^{4}$ Draco Pharamaceuticals, Lund, Sweden.

\begin{abstract}
Summary: Endobronchial and nasal mucosa biopsies were obtained from 5 patients with clinicallystable, diagnosed asthma (ATS criteria). A comparison was made of the presence and distribution of immunocompetent lymphocytes and macrophages within each sample. The distribution of immunocompetent cells within the nasal biopsies of the asthmatic patients reflected a very similar inflammatory infiltrate to that seen in the bronchial biopsies. Significantly raised numbers of T lymphocytes, CD45RO+ lymphocytes, RFD1 + macrophage-like cells and RFD7 + macrophages were seen in both the nasal mucosa and the bronchial biopsies. Increases in HLA-DR expression were also seen in the nasal mucosa biopsies from asthmatics although the increases over normal did not reach statistical significance.

It is concluded that inflammation present in the nasal mucosa of asymptomatic asthmatics exhibits cellular characteristics also seen in endobronchial biopsies. This observation offers the possibility that mucosal biopsy may be an alternative and less invasive approach for studying the cells involved in the bronchial inflammatory reaction that possibly predisposes asthmatics to bronchial hyper-responsiveness.
\end{abstract}

\section{Introduction}

Although the symptoms of asthma are associated with a Type I hypersensitivity reaction, there is increasing evidence that a separate underlying inflammation may predispose asthmatics to this hyperreactivity. It could be argued therefore that to treat the causes rather than the symptoms of this very common disease, the mechanisms promoting this underlying inflammation must be investigated.

Previous histological and electron microscopic studies of the bronchial wall in asthmatics have revealed the presence of a chronic inflammatory reaction dominated by mononuclear cells. ${ }^{1,2}$ This inflammatory infiltrate has been shown to be present in asymptomatic individuals. ${ }^{3,4}$ Immunohistological investigation of biopsy specimens from the bronchial wall of asthmatics has revealed that this inflammatory response is dominated by $T$ lymphocytes many of which exhibit the phenotype

Correspondence: L.W. Poulter, M.Phil, Ph.D., M.R.C.Path., Department of Immunology, Royal Free Hospital Medical School, Hampstead, London NW3 2QG, UK.

Accepted: 6 March 1991 of immunologically activated cells. ${ }^{5}$ Macrophagelike cells with the phenotype of antigen presenting cells are also present and the immunopathology is further characterized by strong expression of HLA-DR molecules both by the inflammatory cells and the lining epithelial cells of the bronchioles. ${ }^{5}$ Together, these features are indicative of a Type IV hypersensitivity response as seen in other chronic inflammatory diseases. ${ }^{6-8}$

The possibility that $T$ lymphocytes play a central role in the pathogenesis of asthma is supported by three lines of evidence. Firstly, T cells isolated from asthmatic patients have been shown spontaneously to produce increased levels of eosinophil chemotactic factor ${ }^{9}$ and exhibit markers of immunological activation. ${ }^{10}$ Secondly, it has been demonstrated that IgE production is controlled by $\mathrm{T}$ cells and that regulation of this mechanism may be aberrant in asthmatics. ${ }^{11}$ Thirdly, there is now evidence that antigen-specific $T$ cell factors are capable of activating mast cells and causing the release of vasoactive amines. ${ }^{12}$

Together these observations promote the hypothesis that the $T$ cell dominated inflammatory reaction identified in the bronchial walls of asymp- 
tomatic asthmatics may represent the cause of the bronchial hyperreactivity characteristic of these patients, being the 'fertile ground' which predisposes asthmatics to pathological immediate type allergic reactions. ${ }^{5}$

To test this hypothesis there is a need to study this chronic $T$ cell reaction at progressive times in asymptomatic and symptomatic asthmatics and determine relationships between the changing clinical and physiological status of patients and quantifiable parameters of this inflammatory reaction. As multiple repeated bronchial biopsy is not an option on ethical grounds, less invasive sampling approaches must be sought.

This paper investigates the value of biopsy of the nasal mucosa as a potential alternative to bronchial biopsy for the sequential examination of the bronchial inflammation associated with asthma. To this end, matched samples of bronchial tissue and nasal mucosa were obtained from a group of 5 patients with diagnosed asthma and a comparison was made of the cellular immunological features reflected in each sample.

\section{Materials and methods}

\section{Patients and controls}

Five patients, 3 male, 2 female, with diagnosed extrinsic asthma (American Thoracic Society criteria) were recruited. All were clinically stable at the time of study with no exacerbations for the 2 months prior. Data on physiology and medication are given in Table I (two patients had a history of smoking but no discrimination in any results related to smoking were detected). Two patients had a history of allergic rhinitis, but this was quiescent at the time of study; the other 3 were free of any nasal symptoms. Control samples of bronchial tissue were taken from patients attending for bronchoscopy with no history of asthma. Control samples of nasal mucosa were obtained from 5 patients attending for minor surgical procedures to the ear. No control subject had any history of lung disease or an episode of viral infection in the 2 months prior to sampling. No evidence of atopy was present and all were non-smokers, none had any nasal symptoms.

\section{Clinical procedures}

Bronchoscopy was performed with an Olympus fibre optic bronchoscope. Patients received sedation with diazamules $(10 \mathrm{ml}$ intravenously). The nasopharynx was anaesthetized with $10 \%$ lignocaine spray and the bronchoscope introduced through the nose. Following further topical anaesthetic with $0.5 \%$ lignocaine, $2-3$ endobronchial biopsies were obtained from sub-carina using cup forceps. The biopsy was removed via the bronchoscope and placed on saline dampened gauze ready for processing. The bronchoscope was then removed. Using nasal biopsy forceps, a sample of the mucosal lining of the inferior turbinate of the contralateral nostril to that used for bronchoscope entry was obtained. This was placed on saline dampened gauze prior to processing. Control samples of nasal mucosa were obtained in a similas fashion from patients undergoing general anaeso thesia for minor ear surgery.

\section{Preparation of samples}

All fresh biopsies were placed on small pieces of cork covered in $O C T$ mounting medium (BDH Ltd., Poole, Dorset) and frozen in isopentane cooled in a bath of liquid nitrogen. The samples were then stored at or below $-70^{\circ} \mathrm{C}$ until $6 \mu \mathrm{m}$ tissue sections were cut on a cryostat maintained at $-30^{\circ} \mathrm{C}$. Slides were air dried for 30 minutes, fixed in chloroform acetone (1:1) for 5 minutes, wrapped in cling film and stored at $-20^{\circ} \mathrm{C}$ until used.

Table 1 Patients studied

\begin{tabular}{|c|c|c|c|c|c|c|c|c|c|}
\hline Patient & Age & Sex & Smoking & $\begin{array}{c}P D_{20} F E V_{1} \\
\text { (mg histamine) }\end{array}$ & $F E V_{l} / F V C$ & $F E V_{1} \%$ & $\Delta F E V_{1} \%$ & $\begin{array}{c}F E F \\
25 \%-75 \%\end{array}$ & Medication \\
\hline $\begin{array}{l}1 \\
2 \\
3 \\
4 \\
5\end{array}$ & $\begin{array}{l}62 \\
38 \\
22 \\
28 \\
15\end{array}$ & $\begin{array}{l}\mathbf{M} \\
\mathbf{F} \\
\mathbf{M} \\
\mathbf{F} \\
\mathbf{M}\end{array}$ & $\begin{array}{l}20 \text { py(ex) } \\
7 \text { py } \\
\text { No } \\
\text { No } \\
\text { No }\end{array}$ & $\begin{array}{l}0.03 \\
8 \\
0.25 \\
2 \\
4\end{array}$ & $\begin{array}{l}41 \\
77 \\
60 \\
65 \\
88\end{array}$ & $\begin{array}{c}32 \\
115 \\
74.4 \\
103 \\
106\end{array}$ & $\begin{array}{r}57.1 \\
6.4 \\
13.9 \\
18.4 \\
8.2\end{array}$ & $\begin{array}{l}56.8 \\
21.9 \\
34.1 \\
53 \\
17\end{array}$ & $\begin{array}{l}\mathrm{B}_{2} / \mathrm{IS}+ \\
\mathrm{B}_{2} \\
\mathrm{~B}_{2} / \mathrm{IS} \\
\mathrm{B}_{2} / \mathrm{IS} \\
\mathrm{B}_{2}\end{array}$ \\
\hline $\begin{array}{l}\text { Mean } \\
\text { s.d. }\end{array}$ & $\begin{array}{l}33 \\
18.2\end{array}$ & & & $\begin{array}{l}2.86 \\
3.29\end{array}$ & $\begin{array}{l}66.2 \% \\
17.8\end{array}$ & $\begin{array}{l}86.1 \\
33.8\end{array}$ & $\begin{array}{l}20.8 \\
20.84\end{array}$ & $\begin{array}{l}36.6 \\
17.86\end{array}$ & \\
\hline
\end{tabular}

$\mathrm{FEV}_{1}=$ forced expiratory volume in the first second; $\mathrm{PD}_{20} \mathrm{FEV}_{1}=$ provocative dose to reduce $\mathrm{FEV}$ by $20 \%$; $F V C=$ forced vital capacity $; \mathrm{FEF}=$ forced expiratory flow; $\beta 2=\beta 2$ agonists; $I S=$ inhaled steroids; $\Delta=\%$ change in FEV above baseline after inhalation of $400 \mu \mathrm{g}$ of salbutamol by metered dose inhaler; py = packet years. 


\section{Histology/cytology}

Tissue sections from all biopsies were stained with haematoxylin and eosin or toluidine blue to reveal the histological characteristics of the sample.

\section{Immunocytochemistry}

The presence, distribution, and proportions of immunocompetent cells within the cryostat sections of the biopsy specimens were determined using immunocytochemical methods incorporating a panel of monoclonal antibodies (MoAb). These reagents were used in indirect immunoperoxidase methods using goat anti-mouse immunoglobulin second layers conjugated to horseradish peroxidase, with a $\mathrm{DAB} /$ hydrogen peroxide solution used as a developing reagent. CD4:CD8 ratios were determined using double immunofluorescence methods with class specific second layers conjugated to FITC and TRITC. ${ }^{17}$ MoAbs used are listed in Table II. Negative control preparations omitting the first layer MoAb, and positivity controls using sections of human palatine tonsil, were always performed for reference.

\section{Quantification}

Morphological parameters were assessed visually. The distribution and frequency of phenotypically distinct cell types within the tissue sections was determined using image analysis systems (Seescan Imaging Ltd., Cambridge, England). Numbers of cells expressing specific markers were point counted in frame defined areas of the sections. The analyser records the area and divides the number of cells counted by the area of the section framed, thus reducing area to unity. All counts are expressed related to a unit area of $10^{4} / \mu \mathrm{m}^{2}$. In most samples all of the inflammatory area was measured, in others a minimum of triplicate areas taken at random from duplicate sections were analysed. Immunofluorescence preparations were counted visually using a Zeiss fluorescence microscope with epi-illumination and appropriate barrier filters for FITC and TRITC. The expression of HLA-DR on the nasal biopsies was quantified by measuring optical density of the peroxidase reaction product using the image analyser. The areas of epithelium and lamina propria were framed on the computer and optical density related to area was measured for each specimen. Care was taken to ensure that all peroxidase reactions for this analysis were performed at the same time with the same reagents. No counterstaining was used. All samples were analysed 'blind' without knowledge of the subject group from which they came.

\section{Statistical analysis}

Where relevant, significance was determined using Students ' $t$ ' test for non-paired data.

\section{Results}

Histology

Haematoxylin and eosin and toluidine blue staining of cryostat section from bronchial biopsies demonstrated the presence of a mononuclear cell infiltration in the lamina propria of all samples from asthmatic patients (Figure 1a). Control samples of bronchial mucosa showed no signs of inflammation (Figure 1b). Examination of sections of nasal mucosa revealed a similar picture.

Table II Monoclonal antibodies used in this study

\begin{tabular}{|c|c|c|c|c|}
\hline Reagent & $C D$ & $\begin{array}{l}\text { Mol. wt. of } \\
\text { antigen } \\
\text { (kd) }\end{array}$ & Source & Specificity on normal cells \\
\hline RFDR 1 & - & $28 / 33$ & RFHSM & Framework epitope on HLA-DR \\
\hline RFD1 & - & $28 / 33$ & RFHSM & $\begin{array}{l}\text { Epitope on Class II MHC antigen } \\
\text { with expression restricted to dend- } \\
\text { ritic cells and some B cells. }\end{array}$ \\
\hline RFD7 & - & 77 & RFHSM & Mature macrophages \\
\hline RFT4 & CD4 & 55 & RFHSM & Helper/inducer $\mathrm{T}$ cell subset \\
\hline RFT8 & CD8 & $32-33$ & RFHSM & Suppressor/cytotoxic $T$ cell subset \\
\hline Tmix & CD2, 7,8,27 & $46,40,33,55$ & RFHSM & All mature $T$ cells \\
\hline Bmix & CD22,37 & 135,35 & RFHSM & All mature B cells \\
\hline UCHL1 & CD45Ro & 180 & Dr P. Beverley & $\mathrm{T}$ cell subset \\
\hline UCHM1 & CD14 & 55 & Dr Nancy Hogg & Monocytes \\
\hline
\end{tabular}

RFHSM $=$ Royal Free Hospital School of Medicine 
a

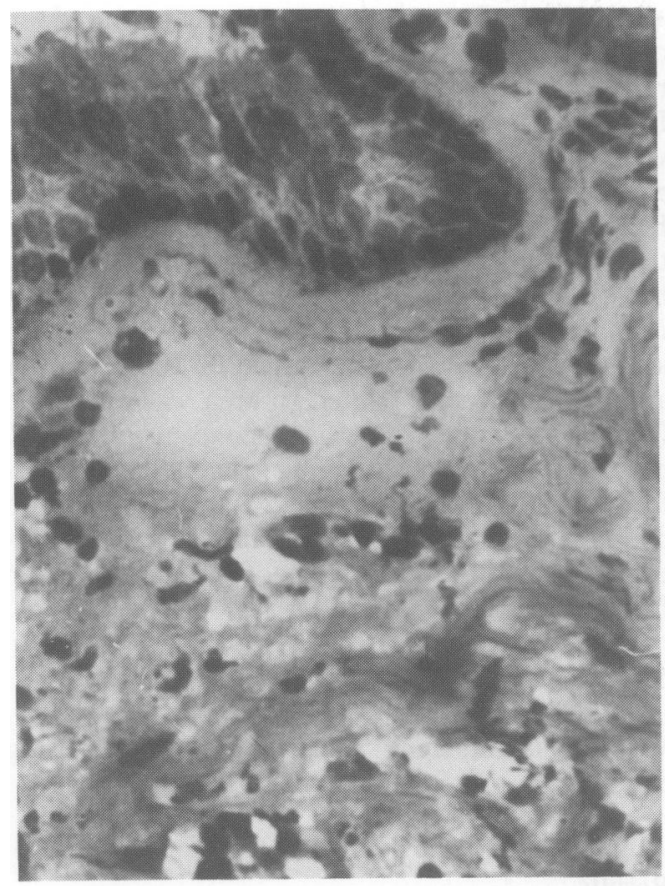

b

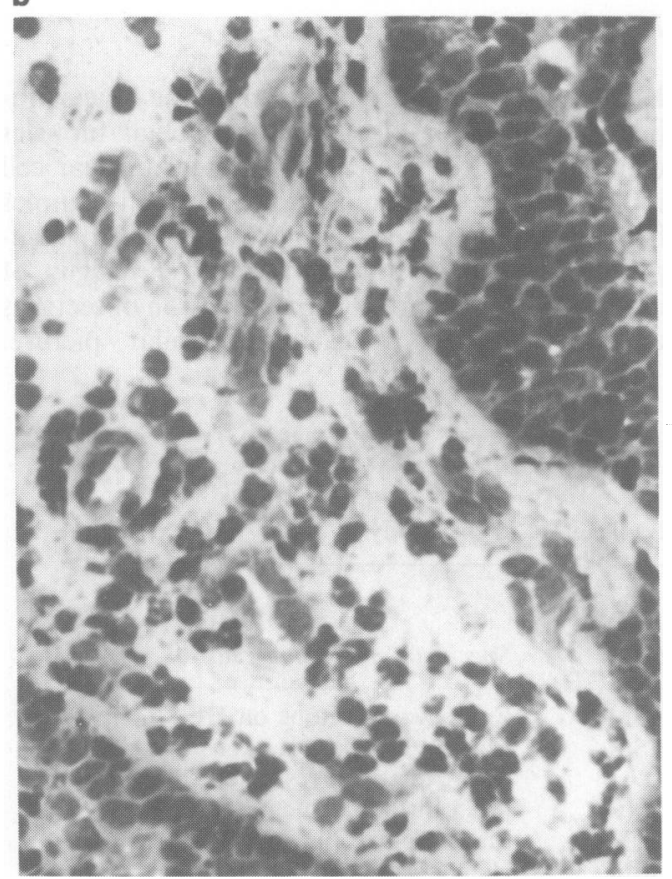

Figure 1 Frozen sections of bronchial biopsies from (b) asthmatic patient, (a) control sample: a mononuclear cell infiltrate is clearly seen in the sample from the asymptomatic asthmatic (Toluidine blue stain, original magnification $\times 400)$.
Accumulations of lymphocytes and macrophages were seen within the lamina propria and there was some evidence of epithelial hyperplasia (Figure 2a). The control nasal samples showed a greater cel- $c$ lularity than the control samples of bronchial tissue but did not exhibit the level of inflammation seen in $\stackrel{9}{\stackrel{9}{+}}$ the nasal biopsies from the asthmatic subjects (Figure 2b).

\section{Immunohistology}

Bronchial biopsies The inflammatory infiltrates seen in the asthmatic endobronchial biopsies showed a major population of T lymphocyes (mean $\pm \overrightarrow{\vec{\omega}}$ s.d., $5.98 \pm 2.58$ cells/unit area compared to $\stackrel{\circ}{\circ}$ $1.47 \pm 0.4$ in controls, $P<0.01$ ) (Table III). There 8 was a dominance of CD4 + ve cells in $3 / 5$ cases and 3 . even proportions of CD4 and CD8 cells in the other 9 two. In all cases $>80 \%$ of lymphocytes expressed CD45Ro antigen, such cells appearing in the

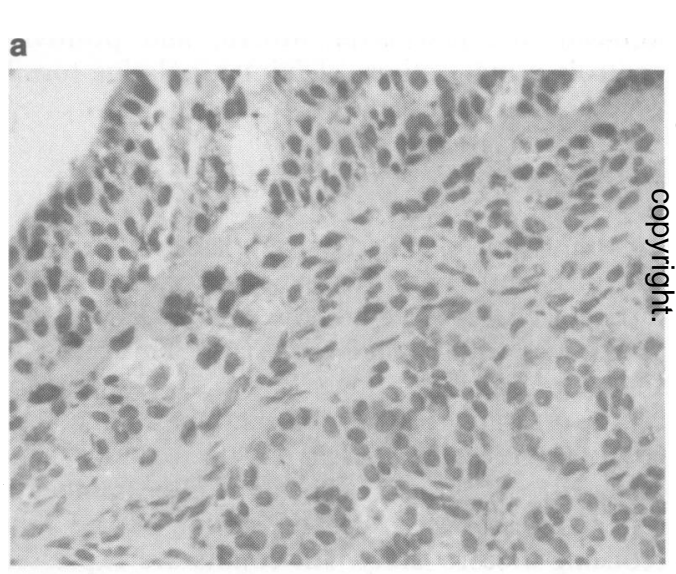

b

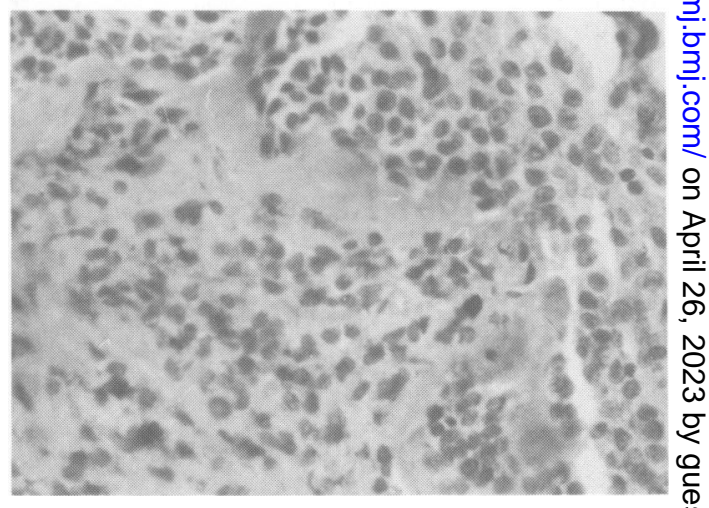

Figure 2 Frozen sections of nasal mucosa taken from (b) $\stackrel{\mathscr{C}}{\rightarrow}$ asthmatic patient, (a) non-asthmatic control: increased $T$ numbers of mononuclear cells are present in sample (b) (Toluidine blue stain, original magnification $\times 400$ ). 
lamina propria and epithelium. There were significant increases in numbers of CD45Ro $+T$ cells (4.17 \pm 2.8 cells/unit area in asthmatics, $0.84 \pm 0.13$ cells/unit area in controls, $P<0.001)$. RFD1 + ve macrophage-like cells were seen in significant numbers in all asthmatic bronchial biopsies and in $3 / 5$ cases constituted the major population of non-lymphoid cells (mean \pm s.d. $2.19 \pm 1.0$ cells/ unit area). No RFD1 + cells were seen in the control biopsies. RFD7 + cells were identified in $4 / 5$ asthmatic samples (Table III) yet the increased incidence of these cells did not reach statistical significance over the controls.

Nasal mucosa Immuno-histological studies of nasal biopsies also revealed differences between the normal samples and asthmatics. The asthmatics had significant increases in the number of $T$ cells $(P<0.005)$, CD45Ro + cells $(P<0.05)$ were observed (Table IV). No difference in the numbers of CD14 + monocytes was recorded. The CD45Ro + cells in the asthmatics nasal tissue were again present in both the lamina propria and in the epithelium (Figure 3b). CD4:CD8 ratios were variable. Two patients showed a slight CD8 dominance and 1 patient showed a ratio of $2: 1$. The other 3 asthmatic patients exhibited equal properties of CD4 + and CD8 + cells. No difference in the small numbers of CD14 + cells present was noted (Table IV). Overall, a close similarity was seen in the distribution of lymphocyte and macrophage sub-sets in the bronchial and nasal biopsies from asthmatic patients.

\section{HLA-DR expression on nasal mucosa}

As raised expression of HLA-DR antigens has previously been shown to be a feature of bronchial tissue from asthmatics, ${ }^{5}$ HLA-DR expression was determined in all nasal biopsies using optical density measurements on the image analysis

Table III Incidence of immunocompetent cells in endobronchial biopsy

\begin{tabular}{lccc}
\hline & $\begin{array}{c}\text { Asthmatic } \\
(n=5)\end{array}$ & $\begin{array}{c}\text { Control } \\
(n=4)\end{array}$ & $P$ \\
\hline $\begin{array}{c}\text { T cells } \\
\begin{array}{c}\text { CD45Ro + } \\
\text { lymphocytes }\end{array}\end{array}$ & $\begin{array}{l}5.98 \pm 2.58 * \\
4.17 \pm 2.8\end{array}$ & $\begin{array}{l}1.47 \pm 0.4 \\
0.84 \pm 0.13\end{array}$ & $<0.01$ \\
$\begin{array}{c}\text { RFD1 + } \\
\text { macrophages }\end{array}$ & $2.19 \pm 1.0$ & NPC & - \\
$\begin{array}{c}\text { RFD7 + } \\
\text { macrophages }\end{array}$ & $1.88 \pm 1.3$ & $0.76 \pm 0.31$ & NS \\
$\begin{array}{c}\text { CD14 + } \\
\text { D14 }\end{array}$ & $0.4 \pm 0.3$ & $>0.2$ & - \\
\hline
\end{tabular}

*Mean \pm s.d. number of cells per $10^{4} \mu \mathrm{m}^{2}$. Calculated from 3 areas measured in each sample within group. $\mathrm{NPC}=$ no positive cells; NS $=$ not significant.
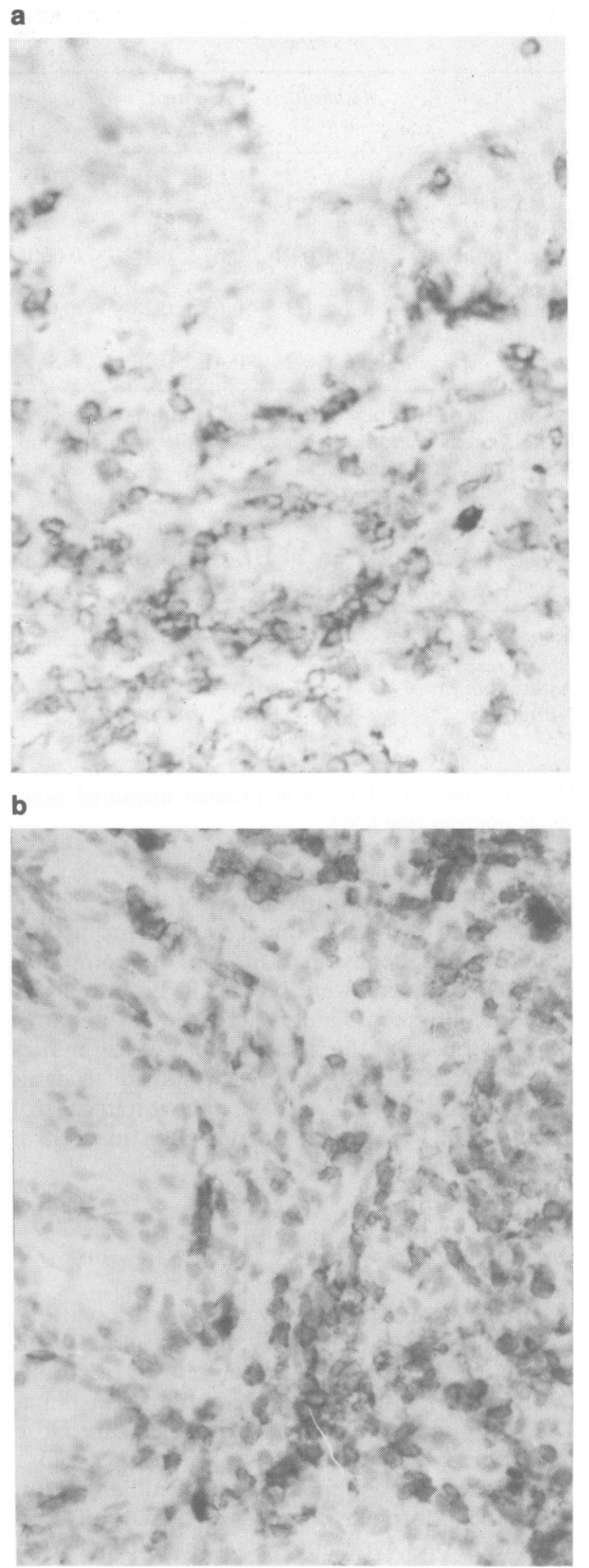

Figure 3 Immunoperoxidase staining using MoAb CD45Ro on frozen sections of (a) bronchial biopsy, (b) nasal mucosa from asthmatic patients: extensive numbers of positive lymphocytes are seen in the lamina propria and epithelium (original magnification $\times 250$ ). 
Table IV Incidence of immunocompetent cells in nasal biopsy

\begin{tabular}{lccc}
\hline & $\begin{array}{c}\text { Asthmatic } \\
(n=5)\end{array}$ & $\begin{array}{c}\text { Control } \\
(n=4)\end{array}$ & $P$ \\
\hline T cells & $10.2 \pm 3.3^{*}$ & $2.8 \pm 1.18$ & $<0.005$ \\
$\begin{array}{l}\text { CD45Ro + } \\
\text { RFD1 + } \\
\text { macrophages }\end{array}$ & $5.61 \pm 2.1$ & $2.59 \pm 1.3$ & $<0.05$ \\
$\begin{array}{c}\text { RFD7 + } \\
\text { macrophages }\end{array}$ & $3.7 \pm 1.7$ & $0.63 \pm 0.28$ & $<0.005$ \\
$\begin{array}{c}\text { CD14 + cells } \\
\text { a }\end{array}$ & $0.56 \pm 0.2$ & $0.41 \pm 0.29$ & $\mathrm{NS}$ \\
\hline
\end{tabular}

*Mean \pm s.d. number of cells per $10^{4} \mu \mathrm{m}^{2}$. Calculated from 3 areas measured in each sample within group. NS $=$ not significant

Table V Optical density of HLA-DR expression/unit area in nasal mucosa

\begin{tabular}{lcc}
\hline Sample & Lamina propria & Epithelium \\
\hline Asthmatic & $5.23 \pm 0.96^{*}$ & $6.03 \pm 1.04$ \\
Normal & $3.8 \pm 1.6$ & $4.69 \pm 1.6$ \\
$P=$ & $>0.05$ & $>0.05$
\end{tabular}

*Relative density of reaction product measured using image analysis (see text).

system. Readings were taken both of the epithelium and of areas within the lamina propria, the distinction being made by marking on the computer. HLA-DR antigens were present in both areas of the control tissues (Table V). This level of expression was raised in the nasal mucosa of asthmatics but this increase did not reach statistical significance as levels of HLA-DR expression in control nasal tissue were much greater than in control bronchial tissue.

\section{Discussion}

Results presented here firstly confirm observations made previously ${ }^{5}$ that signs of a chronic $T$ cell dominated inflammation are present in the bronchial tissue of patients with asymptomatic asthma. The study goes on to show that there are close similarities between the tissues of the nasal mucosa in asymptomatic asthmatics and the inflammation seen in endobronchial biopsies. Specifically, an infiltration of $\mathrm{T}$ lymphocytes, a raised proportion of lymphocytes expressing CD45Ro antigen and increased numbers of RFD1 + macrophages were all seen in samples of both nasal mucosa and bronchial tissue taken from asymptomatic asthmatics. The limited number of patients investigated made correlation of specific parameters difficult. Without further studies, conclusions should be drawn with caution.

There is evidence from the present study to $c$ support the hypothesis that immunopathological changes can be observed within the nasal mucosa of asymptomatic asthmatics that are similar to the inflammatory changes seen in the bronchioles. Significant increases over normal in the numbers of $T$ lymphocytes, and macrophage-like cells, including a subset expressing phenotypic characteristics of antigen-presenting cells (MoAb RFDl +), ${ }^{14}$ were observed in all samples of nasal mucosa obtained from asymptomatic asthmatics. Increase in the expression of lymphocyte 'memory cell' antigen (CD45Ro) ${ }^{15}$ was also noted. Raised expression of HLA-DR antigens was also seen. All of these changes are consistent with the immunopathology of the asthmatic bronchial tissue seen in this study and reported previously. ${ }^{5}$ Eosinophil numbers were not quantified. This might be a valuable addition to further studies.

Other workers have demonstrated an increased reactivity in circulating lymphocytes of asthmatics, in terms of expression of activation markers, ${ }^{10}$ and the production of eosinophil chemotactic factors. There is also no doubt that asthmatic individuals can exhibit atopy in terms of allergic skin tesp reactivity, some workers arguing that all asthma tics may be atopic. ${ }^{16}$ Raised levels of IgE in the circulation are also common. ${ }^{17}$ It is clear therefore that the immunological aberrations associated with this disease are not restricted to the bronchioles of the lung. The presence of sub-clinical inflammation in the nasal mucosa (an area also exposed to environmental antigens) might thus be anticipated. The two asthmatic patients having allergic rhinitis could not be distinguished in any way from the 3 without frank nasal symptoms, therefore it is unlikely that the inflammation in the nasal mucosa of the asthmatics resulted solely from another clinical problem. There would be value, however, in repeating these studies on a group of atopic, non-asthmatic individuals where the atopy component of nasal inflammation could be assessed.

With specific regard to $T$ cells, it has been suggested that aberrations in $\mathrm{T}$ cell control of $\operatorname{IgE}$ production occur in asthma; ${ }^{11}$ that $T$ cells may release chemotactic factors for other inflammatory cells, ${ }^{12}$ and may regulate the release of vasoactive amines from mast cells., ${ }^{912}$ Indeed, correlation has been reported between increases in bronchoalveolar lavage lymphocytes and mast cells in other lung diseases. ${ }^{18}$ Together, these observations lead to the conclusion that an understanding of the role of $T$ cells in asthma is crucial to an insight into pathogenesis. Of particular interest is the presence of large numbers of CD45Ro $+T$ cells in both the 
nose and the lung. As CD45 has been shown to be a protein tyrosine phosphatase ${ }^{19}$ the increased expression of this molecule may be responsible for altered regulation of signalling between lymphocytes $^{20}$ and thus the characteristic expression of 'hypersensitivity' in asthmatics.

The demonstration in this paper that infiltrates of $T$ cells appear in the nasal mucosa of asthmatics identifies a source of these cells that requires the minimum of invasive technique and may be of value in the study of pathogenesis and the sequential monitoring of therapy. Further studies (Poulter et al., in preparation) have characterized the phenotype of both bronchial and nasal $T$ cells from asthmatics in detail and have revealed that the $T$ cells infiltrating these different tissues appear antigenically indistinguishable. Overall, it can be concluded that nasal biopsy might offer an alternative tissue for investigating the underlying, chronic inflammation in asthmatics. Furthermore, this result also leads to the conclusion that such inflammation is not solely restricted to the bronchioles and, as with atopic reactions observed on the skin, may reflect a systemic component of the asthma syndrome.

\section{Acknowledgements}

This work was supported by a Frank Peacock Fellowship from the Royal College of Physicians to L.W. Poulter and by A.B. Draco (subsidiary to ASTRA) Lund, Sweden; C. Burke is supported by the Royal College of Surgeons of Ireland. The authors acknowledge the valuable assistance of Nurse Mary Toole and the support of Mr Kieran Hickey and the Eastern Health Board, Dublin.

\section{References}

1. Dunnill, M.S. The Pathology of Asthma. In: Middleton, E., Reed, C.E. \& Ellis, E.F. (eds) Allergy, Principles and Practice. C.V. Mosby, St Louis, MO, 1978, pp. 678-686.

2. Laitinen, L.A., Heino, M., Laitinen, T. et al. Damage of the airway epithelium and bronchial reactivity in patients with asthma. Am Rev Resp Dis 1985, 131: 599-606.

3. Beasley, R., Roche, W.R., Roberts, J.A. \& Holgate, S.T. Cellular events in the bronchi in mild asthma and after bronchial provocation. Am Rev Resp Dis 1989, 139: 806-817.

4. Lundgren, R., Soberberg, M., Horstedt, P. \& Stenling, R. Morphological studies of bronchial mucosal biopsies from asthmatics before and after 10 years of treatment with inhaled steroids. Eur Resp J 1988, 1: 883-889.

5. Poulter, L.W., Power, C. \& Burke, C. The relationship between bronchial immunopathology and hyperresponsiveness in asthma. Eur Resp J 1990, 3: 792-799.

6. Duke, O., Panayi, G., Janossy, G. \& Poulter, L.W. An immuno-histological analysis of lymphocyte subpopulations and their microenvironment in the synovial membranes of patients with rheumatoid arthritis using monoclonal antibodies. Clin Exp Immunol 1982, 49: 22-28.

7. Collings, L.A., Tidman, N. \& Poulter, L.W. Quantitative differences in the expression of Class II MHC antigens involved in the skin lesions of tuberculoid and lepromatous leprosy. Clin Exp Immunol 1985, 61: 58-64.

8. Poulter, L.W. \& Lehner, T. Immunohistology of oral lesions from patients with recurrent oral ulcers and Behcet's syndrome. Clin Exp Immunol 1989, 78: 189-195.

9. Parish, W.E. T lymphocyte substances controlling eosinophilia. Clin Allergy 1982, 12: 47-50.

10. Corrigan, C.J., Hartnell, A. \& Kay, A.B. T lymphocyte activation in acute severe asthma. Lancet 1988, i: 1129-1131.

11. Snapper, C.M., Finelman, F.D. \& Paul, W.E. Regulation of $\mathrm{IgG}^{1}$ and $\mathrm{IgE}$ production by interleukin 4. Immunol Rev 1988 , 102: $51-75$.

12. Askenase, P.W. \& van Loveren, H. Delayed type hypersensitivity: activation of mast cells by antigen-specific $\mathrm{T}$ cell factors. Immunol Today 1983, 4: 259-264.

13. Janossy, G., Bofill, M. \& Poulter, L.W. Two-colour immunofluorescence analysis with monoclonal antibodies in histology. In: Polak, J. \& Van Noorden, S. (eds) Immunocytochemistry Today. Wright \& Sons, Bristol, 1986, pp. 438-455.

14. Poulter, L.W., Campbell, D.A., Munro, C. \& Janossy, G. Discrimination of human macrophages and dendritic cells using monoclonal antibodies. Scand J Immunol 1986, 24: $351-359$.

15. Akbar, A., Terry, L., Timms, A., Beverley, P.C.L. \& Janossy, G. Loss of CD45R and gain of UCHL1 reactivity is a feature of primed T cells. J Immunol 1988, 140: 1-8.

16. Burrows, B., Martinex, F.D., Halonen, M., Barbee, R.A. \& Cline, M.G. Association of asthma with serum IgE levels and skin test reactivity to allergies. $N$ Engl $J$ Med 1989, 320: 271-277.

17. Rowe, D.S. \& Wood, C.B.S. The measurement of serum immunoglobulin $\mathrm{E}$ levels in healthy adults and children, and in children with allergic asthma. Int Arch Allergy Appl Immunol 1970, 39: 1-5.

18. Rottoli, P., Rottoli, L., Perari, M.G., Collodoro, A., Carriero, G. \& Bianco, S. Mast cells in broncho-alveolar lavage in sarcoidosis. Correlation with alveolar lymphocytes. Respiration, 1988, 54 (Suppl. 1): 42-48.

19. Tonks, N.K., Charbonneau, H., Diltz, C.D., Fischer, E.H. \& Walsh, K.A. Demonstration that the leukocyte common antigen CD45 is a protein tyrosine phosphatase. Biochemistry 1988, 27: 8695-8699.

20. Clarke, E.A. \& Ledbetter, J.A. Leukocyte cell surface enzymology: CD45 (LCA, T200) is a protein tyrosine phosphatase. Immunol Today 1989, 10: 225-228. 